\title{
PERGAMON
}

www.elsevier.com/locate/watres

\section{OXIDATIVE DECOLORIZATION OF DIRECT LIGHT RED F3B DYE AT NATURAL MANGANESE MINERAL SURFACE}

\author{
RUIXIA LIU*M and HONGXIAO TANG ${ }^{\mathrm{M}}$ \\ State Key Laboratory of Environmental Aquatic Chemistry, Research Center for Eco-Environmental \\ Sciences, Chinese Academy of Sciences, PO Box 2871, Beijing, 100085, People's Republic of China
}

(First received 9 August 1999; accepted in revised form 20 January 2000)

\begin{abstract}
In this paper, the characteristics of natural manganese mineral collected from Guangxi Province, China, including crystalline properties, elemental composition, organic substrates content $(0.17 \%)$ and BET surface area $\left(29.8 \mathrm{~m}^{2} / \mathrm{g}\right)$, were determined. By X-ray powder diffraction and fluorescence spectrograph analysis, it is shown that manganese oxide in the natural mineral exists in the crystal structure of $\alpha-\mathrm{Mn}_{2} \mathrm{O}_{3}$ and the contents of manganese (II) and manganese (IV) oxides are 4.6 and $42.6 \%$, respectively. The solubility experiments show that manganese dissolved in solution can be ignored at a higher $\mathrm{pH}$ value, but its significant solubility is observed with the decrease of $\mathrm{pH}$ value. Moreover, the decolorization properties of direct light red F3B dye on natural manganese mineral surface were studied by batch technique. The effects of $\mathrm{pH}$ value, temperature, inert electrolyte, light, particles concentration and size, the presence of calcium and phosphate as well as oxygen on the decolorization efficiency of the dye were investigated in detail. The results show that the decolorization of the dye is strongly dependent on $\mathrm{pH}$ value, with lower decolorization percentage at higher $\mathrm{pH}$ values, and the higher concentration of inert electrolyte and temperature favor the decolorization reaction of the dye on the particle surface. By Arrhenius Equation, the apparent activation energy is found to be at $71.7 \mathrm{~kJ} / \mathrm{mol}$, indicating the surface chemical reaction as a rate-limiting step in the overall interface process. The illumination enhances the surface chemical reaction of the dye on manganese mineral particles. The decolorization rate of the dye compound is increased with the increase of particle concentration and the decrease of size since the available surface sites grow in number. The presence of phosphate greatly inhibits the decolorization reaction by competitive adsorption on the mineral surface with the dye anion, while the addition of calcium promotes the decolorization rate of direct light red F3B dye. (C) 2000 Elsevier Science Ltd. All rights reserved
\end{abstract}

Key words - natural manganese mineral, characteristic, decolorization properties, direct light red F3B dye, effect factors

\section{INTRODUCTION}

Synthetic textile dyes and other industrial dyestuffs constitute the largest group of chemicals in China. These chemicals may be released to the aquatic environment in the water stream of the dying operation and result in the natural water contamination. Due to their toxicity to humans and to aquatic life as well as poor degradability, the fate of the dye compounds is a subject of considerable interest and the destruction of these pollutants has been taking on increasing importance in recent years.

Usually, the treatment methods for dye effluents include physical-chemical techniques (Lin and Peng, 1994; Meyer et al., 1992) destroying the color groups and biochemical process (Specchia and Gia-

\footnotetext{
*Author to whom all correspondence should be addressed. Tel.: +86-10-62923541; fax: + 86-10-62923563; e-mail: rachel@mail.rcees.ac.cn
}

netto, 1984; Sun et al., 1991) mineralizing the colorless organic intermediates. The chemical oxidation is one of the competitive processes for the degradation of organic pollutants. It includes homogeneous oxidation such as $\mathrm{UV} / \mathrm{O}_{3}$ and $\mathrm{H}_{2} \mathrm{O}_{2} / \mathrm{Fe}^{2+}$ (Kuo, 1992) and heterogeneous photocatalytic oxidation using CdS (Davis and Huang, 1990), $\mathrm{Fe}_{2} \mathrm{O}_{3}$ and $\mathrm{ZnO}$ (Kormann et al., 1989) and $\mathrm{TiO}_{2}$ (Choi et al., 1994; Carraway et al., 1994; Reynaldo et al., 1995) as catalysts. But these methods have not found widespread application because of the higher cost.

A number of reviews on the reduction and dissolution of natural minerals as well as adsorption and electron transfer of organic compounds at metal oxide surface have been published (Hering and Stumm, 1990; Stone, 1986). It has been pointed out that manganese (III/IV) oxide particles in natural waters participate in a number of oxidation reactions involving both organic and inorganic com- 
pounds, increasing the mobility of manganese and its availability to organisms. Although the reduction reactions occurring at the manganese oxide/water interface have received considerable attention for many years (Stone and Morgan, 1984a,b; Oscarson et al., 1980), the oxidation of organic pollutants at the natural manganese mineral surface as a degradable pathway is poorly studied.

The natural manganese minerals containing manganese(IV) are in abundance in China and may be potential oxidizing agents for organic pollutants. Therefore, the main objectives of this study are to assess whether direct light red F3B dye (DLR) can be oxidatively degraded by the natural manganese mineral, to investigate the decolorization properties of the dye at the mineral surface and to discuss the effects of $\mathrm{pH}$ value, temperature, inert electrolyte, illumination, the presence of other ions and oxygen as well as the mineral particle concentration and size on the decolorization efficiency.

\section{MATERIAL AND EXPERIMENTAL METHODS}

\section{Materials}

The natural manganese mineral samples were collected from Guangxi Province, China, then were ground and passed though 200,100, 60, 20 mesh stainless steel sieves, respectively. Direct light red F3B dye was purchased from Chinese Knitting Mill. Stock solution $(1000 \mathrm{mg} / \mathrm{l})$ of the dye was prepared with deionized water, and further diluted to various concentrations in the experiment. All the other chemicals used in this study were of analytical reagent grade.

\section{Characterization of natural manganese mineral}

The natural manganese mineral was characterized by Xray powder diffraction (Model D/Max-RC). The elemental composition with the exception of manganese and BET surface area $\left(29.8 \mathrm{~m}^{2} / \mathrm{g}\right)$ of the manganese mineral were determined using the X-ray fluorescence spectrograph (Model 3070) and the $\mathrm{N}_{2} / \mathrm{BET}$ method (ASAP Model 2000), respectively. The total manganese and oxidation state manganese of the mineral were measured by atomic absorption spectrophotometer (AAS, Model Z-6100)) and back-titration of excess oxalate with permanganate. The organic substrates content $(0.17 \%)$ in the mineral was obtained using the potassium dichromate method.

Solubility of manganese in mineral at various $\mathrm{pHs}$

The solubility test was performed in batch systems. Each sample suspensions with $20 \mathrm{mg} / \mathrm{l}$ or without dye compounds, adjusted to the pHs between 2 and 8 with diluted $\mathrm{NaOH}$ and $\mathrm{HNO}_{3}$, contained $2 \mathrm{~g} / 1$ manganese mineral particle (200 mesh). All the slurries were shaken at a $25 \pm 1{ }^{\circ} \mathrm{C}$ constant temperature air-bath (Model HZQ-C). Suspension aliquots were collected at timed interval and filtered through a $0.45-\mu \mathrm{m}$ syringe-end filter. Then, the concentration of manganese in filtrate was analyzed by AAS. No background electrolyte was used in this experiment.

Chemical oxidation studies of dye compound at mineral water interface

Batch technique of direct light red F3B dye oxidation was applied in this experiment. A $200 \mathrm{ml}$ volume of dye solution, previously adjusted to a fixed $\mathrm{pH}$ value with diluted $\mathrm{NaOH}$ and $\mathrm{HNO}_{3}$, was added to a $250-\mathrm{ml}$ beaker containing 2, 4 and $6 \mathrm{~g}$ of the manganese mineral samples. The suspensions were immediately stirred under room light at $25 \pm 1{ }^{\circ} \mathrm{C}$, and the aliquots were collected at timed intervals and filtered through a $0.45-\mu \mathrm{m}$ syringe-end filter. Then the concentration of the dye in filtrate was determined by UV-VIS Spectrophotometer (Model DU-650). According to the above process, the effects of manganese particle concentration and size, $\mathrm{pH}$ value, inert electrolyte, temperature, the presence of other ions and oxygen on the oxidative decolorization reaction of the dye at the mineral surface were investigated.

Photooxidation studies of dye compound at mineral/water interface

A $400 \mathrm{ml}$ volume of $20 \mathrm{mg} / 1$ direct light red F3B dye solution was directly prepared in a photoreactor, and a $2 \mathrm{~g} / \mathrm{l}$ suspension of manganese powder was used in each batch experiment. The illumination was provided by a 500 W middle-pressure mercury lamp. A glass cold trap that absorbs ultraviolet radiation $(<330 \mathrm{~nm})$ was used to shield the lamp inside the reactor so that the radiation of $330-450 \mathrm{~nm}$ was available for the reaction system. The temperature of the suspension was kept at $20.0 \pm 0.1^{\circ} \mathrm{C}$ using the cooling water bath and air was constantly purged into the reactor at $240 \mathrm{ml} / \mathrm{min}$. After the reaction started, the samples were withdrawn at regular intervals, filtered through $0.45-\mu \mathrm{m}$ membranes and analyzed. The effect of illumination on the interaction of the dye on the manganese particle surface was studied. The dark experiment was conducted under the conditions similar to photooxidation studies except with no starting mercury lamp.

\section{RESULTS AND DISCUSSION}

\section{Manganese minerial characterization}

$\mathrm{X}$-ray diffraction spectrum of the natural manganese minerial is shown in Fig. 1. It can be seen that even if the minerial contains a lower silicon component, the stronger peaks of $\mathrm{SiO}_{2}$ are produced at $d$-spacing of $3.345,4.283$ and $2.457 \AA$ due to its perfect crystalline properties. In addition, the three major peaks of manganese oxide are found, a strongest peak at a spacing of $4.748 \AA$, a broad weak peak at $9.522 \AA$ followed by a weak peak at 2.373 $\AA$. These $d$-spacings of peaks are consistent with those reported for $\alpha-\mathrm{Mn}_{2} \mathrm{O}_{3}\left(\mathrm{MnO} \cdot \mathrm{MnO}_{2}\right)(\mathrm{Yu}$ and Jiang, 1984). Furthermore, the appearance of peaks

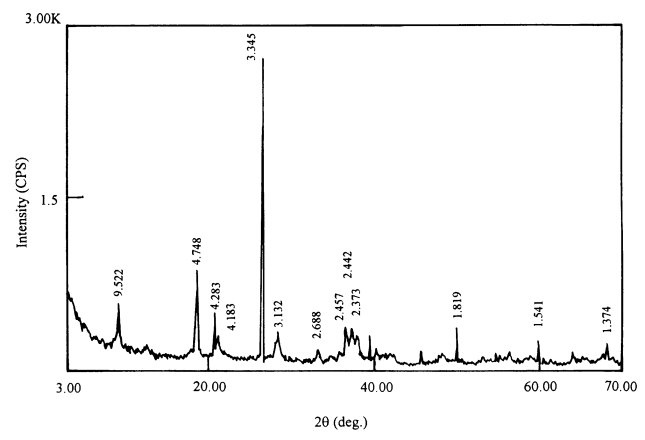

Fig. 1. X-ray diffraction spectrum of the natural manganese minerial. 
Table 1. Elemental composition of natural manganese mineral

\begin{tabular}{lcccccccccc}
\hline Elements & $\mathrm{Mn}$ & $\mathrm{Fe}$ & $\mathrm{Si}$ & $\mathrm{Al}$ & $\mathrm{Ca}$ & $\mathrm{Mg}$ & $\mathrm{K}$ & $\mathrm{Na}$ & $\mathrm{P}$ & $\mathrm{S}$ \\
\hline Content (\%) & 30.6 & 7.26 & 8.66 & 3.05 & 0.39 & 0.28 & 0.42 & 0.23 & 0.14 & 0.11 \\
\hline
\end{tabular}

at $2.442,4.183$ and $2.688 \AA$ is mainly contributed to by the presence of ferrihydrite in the mineral.

The elemental composition of the natural manganese mineral is summarized in Table 1. The results, combined with X-ray diffraction analysis, show that manganese, ferric and silicon oxides are major mineral components. According to the total manganese and oxidation state of manganese analysis, the contents of manganese (II) and manganese (IV) oxides in the mineral are 4.6 and $42.6 \%$. It has been pointed out that $\alpha-\mathrm{Mn}_{2} \mathrm{O}_{3}$ possesses the ring spacenetwork structure in which some ions with larger radius such as $\mathrm{Ba}^{2+}, \mathrm{Ca}^{2+}, \mathrm{Na}^{+}$and $\mathrm{K}^{+}$can be involved. To maintain charge balance in the ring, the lower valent state manganese (II/III) must be contained in the $\mathrm{MnO}_{6}$ octahedral structure of $\alpha$ $\mathrm{Mn}_{2} \mathrm{O}_{3}$. All the above evidences are consistent with the characterization of $\alpha-\mathrm{Mn}_{2} \mathrm{O}_{3}$

\section{Solubility of manganese mineral}

In the previous paper (Stone and Morgan, 1984b; Sunda and Kieber, 1994), it has been shown that manganese (III/IV) oxides are insoluble and in blank experiments without organic reductant, the dissolved manganese is only less than $3 \%$ of the total manganese added (at $\mathrm{pH}$ 7.2). The dissolution of manganese oxide is enhanced by a variety of simple organic compounds having structures similar to organic material in natural water. The results of the dissolution test in the present study (see Fig. 2) show that the manganese dissolved in solution can be ignored at a higher $\mathrm{pH}$ value, while its significant solubility is observed with the decrease of $\mathrm{pH}$ value. This phenomenon is mainly attributed to two important factors: (1) the release of $\mathrm{Mn}(\mathrm{II})$ having high mobility from the crystal structure of $\alpha-\mathrm{Mn}_{2} \mathrm{O}_{3}$

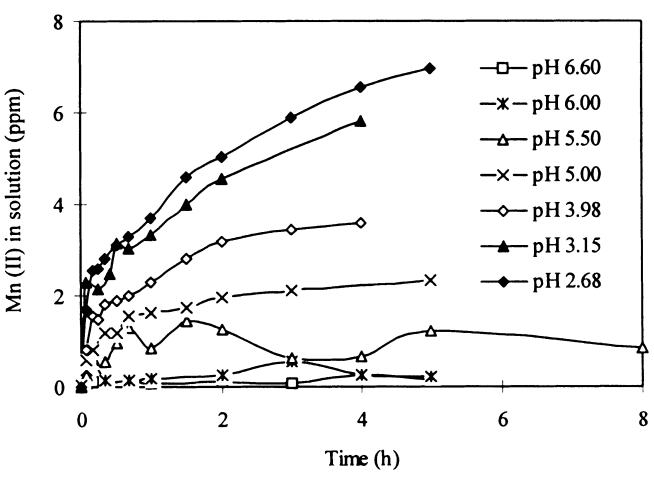

Fig. 2. Solubility of manganese oxide in natural manganese mineral as a function of time at various $\mathrm{pH}$ values, no addition of DLR. in acidic aqueous solution; (2) the reduction of manganese(IV) to $\mathrm{Mn}(\mathrm{II})$ by the organic substrates of a natural mineral. Comparatively, the role of the former process is more obvious for the manganese oxide dissolution because the natural manganese mineral contains lower organic substrates. Moreover, as shown in Fig. 3, the amount of manganese dissolved in solution increases considerably with the addition of DLR dye. It is indicated that the dye compound can reduce manganese (IV) oxide to soluble manganese (II), in other words, the oxidative reaction of the dye compound really occurs at the manganese mineral particle surface.

\section{Effect of $p H$ value on the decolorization of $D L R$ dye}

The decolorization efficiency of DLR dye compound on manganese mineral particles surface at various $\mathrm{pHs}$ as a function of the reaction time is shown in Fig. 4. It is obvious that the decolorization rate of the compound remarkably increases as the $\mathrm{pH}$ value decreases from 6 to 3 , then a little change of decolorization percentage is observed below $\mathrm{pH}$ 3.0. This behavior can be mainly explained as the kinetic process of the DLR at the particle surface. The oxidation of organic compound on manganese oxide suspension appears to be a heterogeneous reaction, which can be broadly described as the diffusion of organic compound to particle interface to form a surface complex between the reactants, followed by electron transfer and products release (Wehrli, 1990). The differences of decolorization rate of the dye compound on the manganese mineral particle surface at various $\mathrm{pHs}$ are mainly caused by the effect of $\mathrm{pH}$ value on the above kinetic processes. It is well known that the unbound surface species $(\equiv \mathrm{MnOH})$ can be formed

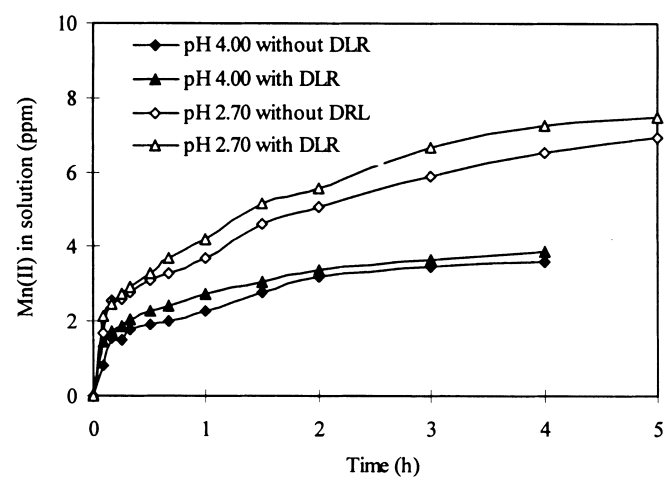

Fig. 3. Comparison of dissolution of manganese oxide in natural manganese mineral, following the addition of 0 and $20 \mathrm{mg} / \mathrm{l} \mathrm{DLR}$. 
on manganese mineral interface at $\mathrm{pH}$ values near $\mathrm{pH}_{\mathrm{zpc}}$. The protonation of the particle surface results in the changes of surface species:

$$
\begin{aligned}
& \equiv \mathrm{MnOH}+\mathrm{H}^{+}=\mathrm{MnOH}_{2}^{+} \\
& \equiv \mathrm{MnOH}=\mathrm{MnO}^{-}+\mathrm{H}^{+}
\end{aligned}
$$

In addition, the protonation of DLR dye compound $(\mathrm{RH})$ in aquatic solution can be expressed as the following equilibrium:

$$
\begin{gathered}
\mathrm{RH}+\mathrm{H}^{+}=\mathrm{RH}_{2}^{+} \\
\mathrm{RH}=\mathrm{R}^{-}+\mathrm{H}^{+}
\end{gathered}
$$

The neutral dye species, formed readily at a lower $\mathrm{pH}$ value, are considerably more hydrophobic than corresponding dye anions, enhancing the force for exclusion from bulk solution. Thus, the protonation level of dye-mineral particle surface complexes and the driving force for the formation of surface complex onto mineral surface sites are influenced by $\mathrm{pH}$ value.

With the increase of protonation level, the electron transfer rate within the dye-particle surface complex is considerably accelerated since oxidisability of manganese (IV) oxide can be sharply enhanced (Stone, 1987). Moreover, the release of manganese (II) and organic intermediates generated in the surface reaction is also affected by the $\mathrm{pH}$ value. The lower hydrogen ion concentration is favorable for the adsorption of $\mathrm{Mn}(\mathrm{II})$ ion on the particles, thereby resulting in the loss of surface sorption sites. In this case, the further adsorption and oxidation of dye compound on the mineral particle interface are greatly inhibited (Waite et al., 1988).

\section{Determination of apparent activation energy}

The temperature is a complicated impact factor on the decolorization of dye compounds on the

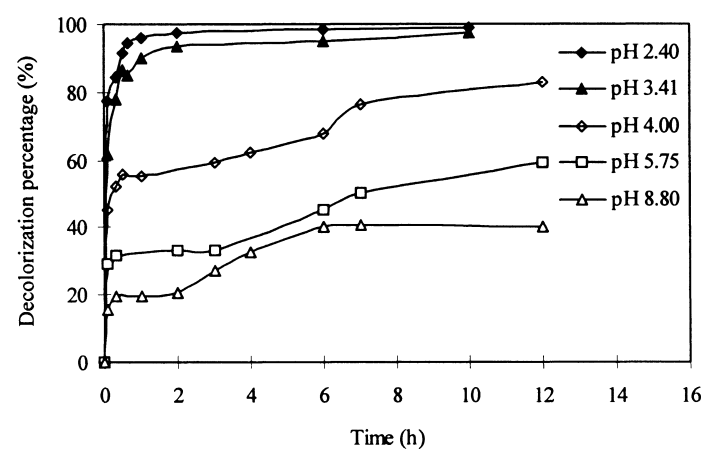

Fig. 4. Decolorization of DLR dye as a function of time at various $\mathrm{pHs}$ (reaction condition: particle concentration $2 \mathrm{~g} / \mathrm{l}$ (200 mesh), temperature $25^{\circ} \mathrm{C}$, DLR dye concentration $20 \mathrm{mg} / \mathrm{l}$. manganese mineral because of the complexity of the kinetic process. It has been known that the energy band gap of manganese oxide with semiconductor characteristic is from 0.26 to $0.7 \mathrm{eV}$ (Strehlow and Cook, 1973), which is low enough to stimulate electrons to a conduction band at room temperature. With increasing temperature, the numbers of activated dye molecules increase and the rate of electrons excited to the conduction band is accelerated so that more than one electron participates in the oxidation-reduction reaction on the particle surface. Thereby, the surface chemical reaction easily occurs at high temperature. As shown in Fig. 5, in higher temperature range from 303 to $333 \mathrm{~K}$, the decolorization efficiency of DLR dye on the manganese mineral particle is strongly temperature-dependent. However, the influence of temperature on the decolorization of the dye compound is relatively insignificant at the initial reaction stage $(<10 \mathrm{~min})$ and in a lower temperature range $(<303 \mathrm{~K})$. This can be explained as the change of interaction mechanism of DLR dye with the particle surface from the fast physisorption to surface chemical reaction.

Measurements of the apparent activation energy support the chemical reaction mechanism between the dye compound and manganese mineral particles. The experimental data in Fig. 5 are treated according to the first order reaction kinetic equation and the results are summarized in Table 2. It is revealed that the interaction of DLR dye with the manganese mineral particles seems consistent with the first order reaction kinetic process. The apparent activation energy, reaction temperature and rate constant are related by the Arrhenius Equation:

$$
d \operatorname{lnk} / d T=E / R T^{2}
$$

where $E$ is apparent activation energy, $k$ is rate constant and $T$ is reaction temperature. The lnk plotted vs $1 / T$ gives a straight line having a slope equal to $E$. The contribution of heat energy from other pro-

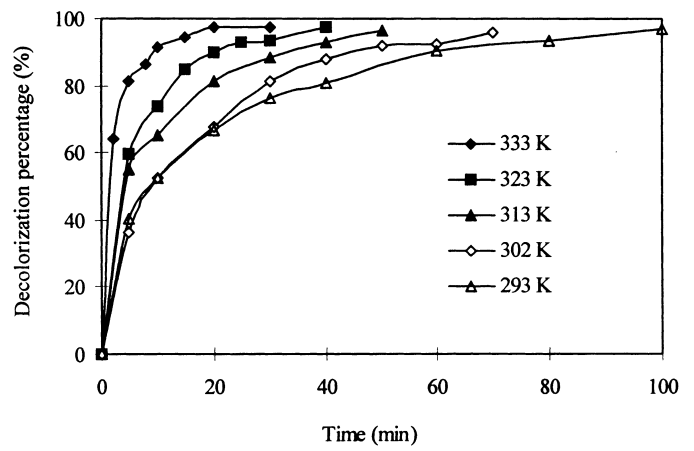

Fig. 5. Effect of reaction temperature on the decolorization of DLR dye (reaction condition: particle concentration $2 \mathrm{~g} / \mathrm{l}$ (200 mesh), $\mathrm{pH}$ 3.50, DLR dye concentration $20 \mathrm{mg} / \mathrm{l})$ 
Table 2. First order reaction kinetic equation of DLR dye on the manganese mineral surface ${ }^{\mathrm{a}}$

\begin{tabular}{lccc}
\hline$T(\mathrm{~K})$ & First order reaction equation & Rate constant $k\left(\mathrm{~min}^{-1}\right)$ & Regression coefficient $r$ \\
\hline 293 & $\ln C_{0} / C_{\mathrm{t}}=0.0366 t$ & 0.0336 & 0.9668 \\
302 & $\ln C_{0} / C_{\mathrm{t}}=0.0481 t$ & 0.0481 & 0.9809 \\
313 & $\ln C_{0} / C_{\mathrm{t}}=0.0698 t$ & 0.0698 & 0.9707 \\
323 & $\ln C_{0} / C_{\mathrm{t}}=0.1002 t$ & 0.1002 & 0.9628 \\
333 & $\ln C_{0} / C_{\mathrm{t}}=0.1626 t$ & 0.1626 & 0.8152 \\
\hline
\end{tabular}

${ }^{\mathrm{a}}$ Reaction conditions: particle concentration $2 \mathrm{~g} / \mathrm{l}$ (200 mesh), pH 3.50, DLR dye concentration $20 \mathrm{mg} / \mathrm{l}$.

cesses such as surface protonation and deprotonation, transfer of dye compound from the bulk phase to the interfacial phase of the mineral particles and the conformation changes of the compound after adsorption would be small (deKeizer et al., 1990). So the apparent activation energy of $71.7 \mathrm{~kJ} / \mathrm{mol}$ derived from the data in Table 2 further indicates that the interface chemical reaction is the dominant interaction mechanism in the overall process.

Photocatalytic oxidation of DLR dye on manganese mineral surface

The curves exhibiting the decolorization degree of DLR dye as a function of reaction time in light and dark cases are shown in Fig. 6. As shown, the effect of light on increasing decolorization rate of the dye compound is evident and the decolorization percentages under dark and light conditions are found to be 40 and $90 \%$ at a reaction time of $4 \mathrm{~h}$. The lightinduced decolorization of DLR dye on the particles is contributed to three possible mechanisms. First, the rate of valence electrons excited to the conduction band, occurring at the manganese mineral particle surface, is accelerated by irradiation. The photo-generated holes are scavenged by readily oxidable dye species and the remaining electrons reduce the high valence manganese at the mineral surface. The second explanation is that electron transfer occurs through a ligand-to-metal charge transfer transition within the surface complex. In the case of light, the excited state surface complex, in which it is likely to transfer electrons from ligand

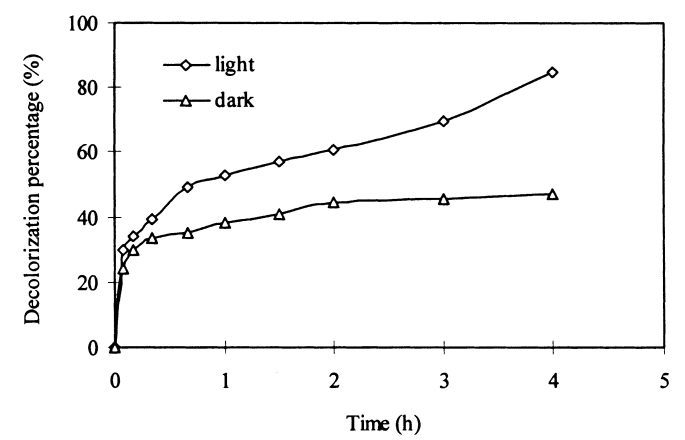

Fig. 6. Comparison of decolorization of DLR dye on manganese mineral surface in light and dark cases (reaction condition: particle concentration $2 \mathrm{~g} / 1$ (200 mesh), temperature $20^{\circ} \mathrm{C} \pm 0.1$, DLR dye concentration $20 \mathrm{mg} /$, $\mathrm{pH}$ 5.75-6.00). to central ion of mineral surface, is formed since the charge transfer band absorbs light. Finally, by illumination of the excitation of $n-\pi^{*}$ and $\pi-\pi^{*}$ transitions of free electrons at oxygen, nitrogen and sulfur atoms involved in DLR dye compound enhances the electron-donating ability of the dye compound. Furthermore, the DLR dye contains four groups of $\mathrm{Ar}-\mathrm{N}=\mathrm{N}-\mathrm{Ar}$ and six aromatic rings with conjugate properties and the $\pi$ electrons in the conjugated system are active and easily excited even if they absorb low light energy.

Effect of inert electrolyte on the decolorization of DLR dye

Figure 7 illustrates the influences of an inert electrolyte on the decolorization of DLR dye at the mineral/water interface. It is evident that the decolorization degree of the dye compound increases dramatically in the presence of $\mathrm{NaNO}_{3}$ as an inert electrolyte, indicating a much greater affinity of DLR dye for the manganese mineral than that of electrolyte ions. The decolorization dependence can be explained by the influence of the inert electrolyte on the adsorption behavior of the dye compound on the mineral particle surface. It has been demonstrated that a specific surface complex of organic compounds on manganese oxide is formed prior to electron transfer (Ulrlch and Stone, 1989). According to surface chemistry theory, an electric double layer is formed at manganese mineral/water interface due to electrostatic interaction. In the presence of $\mathrm{NaNO}_{3}$, the thickness of the diffuse double layer

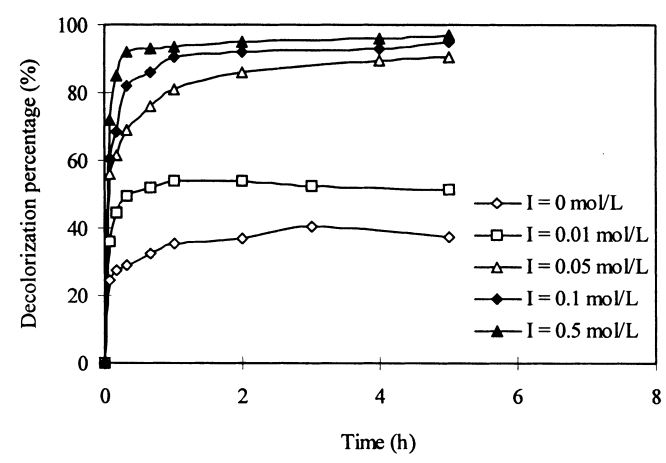

Fig. 7. Decolorization of DLR dye as a function of time in different concentration $\mathrm{NaNO}_{3}$ (reaction condition: particle concentration $2 \mathrm{~g} / 1$ (200 mesh), temperature $25^{\circ} \mathrm{C}$, DLR dye concentration $20 \mathrm{mg} / \mathrm{l}, \mathrm{pH} 8.05)$. 
can be significantly compressed, which is available for the mineral particles and dye molecules to approach each other more closely, leading to the remarkable increase of attractive forces and sorption of the dye molecules on the particle surface. In addition, the solubility of the dye decreases with the increase of electrolyte concentration, which makes the transfer of dye molecules from the solution phase to the particle surface favorable as a result of the hydrophobic effect.

Effect of other ions, oxygen, particle concentration and size on decolorization

A series of experiments were performed in which stock calcium nitrate or sodium phosphate solution was added to the manganese mineral particle suspension prior to the addition of DLR dye. At $\mathrm{pH} 4.00$ and $8.00 \pm 0.25$, phosphate greatly inhibits the decolorization reaction of the dye on the manganese mineral surface. As shown in Fig. 8, the decolorization degree in $0.01 \mathrm{~mol} / 1$ phosphate is $55 \%$ less than that in the absence of phosphate at a reaction time of $4 \mathrm{~h}$. The inhibition is mainly due to competitive adsorption of phosphate with the dye anion on the mineral surface, resulting in the decrease of available surface sites. On the contrary, the addition of $0.01 \mathrm{~mol} / 1$ calcium strongly enhances the decolorization rate of DLR dye as a result of increasing attractive forces between dye molecules and particle surface in the presence of inert electrolyte such as calcium nitrate. So, the presence of the inert electrolyte favors the decolorization reaction of DLR dye, while the phosphate anion, as a result of participating in interfacial adsorption, results in the decrease of DLR dye decolorization efficiency on manganese mineral surface.

Moreover, the influences of manganese mineral particle concentration and size as well as the pre-

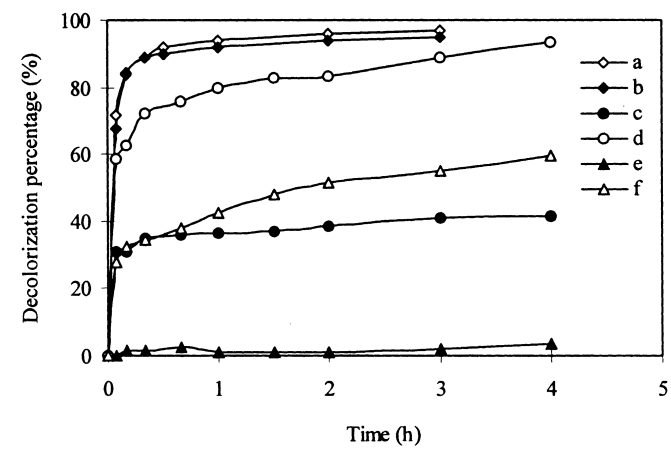

Fig. 8. Effect of phosphate and calcium ions on decolorization of DLR dye as a function of time (reaction condition: particle concentration $2 \mathrm{~g} / 1$ (200 mesh), temperature $25^{\circ} \mathrm{C}$, DLR dye concentration $20 \mathrm{mg} / \mathrm{l}$, (a) $0.01 \mathrm{~mol} / \mathrm{l} \mathrm{Ca}^{2+}$, pH 4.00; (b) $0.01 \mathrm{~mol} / \mathrm{C} \mathrm{Ca}^{2+}, \mathrm{pH} 8.00$; (c) $0.01 \mathrm{~mol} / 1 \mathrm{PO}_{4}^{3-}, \mathrm{pH} 4.00$; (d) no other ions, $\mathrm{pH} 4.00$; (e) $0.01 \mathrm{~mol} / 1 \mathrm{PO}_{4}^{3-}, \mathrm{pH} 8.00$; (f) no other ions, $\mathrm{pH} 8.00$ ). sence of oxygen on the decolorization efficiency were investigated. As is known, the surface adsorption process is necessary for further chemical reaction of the dye compound on the mineral particle interface to occur and the sorption degree is dependent on the surface area and adsorption sites of the adsorbent. It is shown that the decolorization rate rises with the increase of particle concentration and decrease of size as a result of available surface adsorption sites growing in number. The significant differences of decolorization rate of the dye on the manganese mineral surface, with or without oxygen, are not observed.

\section{CONCLUSIONS}

This study proves the importance of natural manganese mineral in the decolorization of DLR dye compound. The investigation on decolorization properties of the dye shows that the manganese mineral, combined with some water treatment technique, may be a kind of effective material for the decolorization of dye compounds in natural water.

Manganese oxide in the natural manganese mineral is possessed of the structure of $\alpha-\mathrm{Mn}_{2} \mathrm{O}_{3}$ and shows good oxidative properties for dye compounds due to a higher content of manganese (IV) oxide in the mineral, 42.6\%. Manganese (II) dissolved in solution can be ignored at a higher $\mathrm{pH}$ value, but its significant solubility is observed with a decrease of $\mathrm{pH}$ value. The $\mathrm{pH}$ value is one of the important effect factors on the decolorization efficiency of DLR dye on a natural manganese mineral, with a higher decolorization percentage at lower $\mathrm{pH}$ values. The higher concentration of inert electrolyte and temperature are available for the decolorization reaction of the dye. The high apparent activation energy found to be $71.7 \mathrm{~kJ} / \mathrm{mol}$, indicates the surface chemical reaction as a rate-limiting step in the overall interface process. The light-induced effect of decolorization for DLR dye on manganese mineral particles is remarkable. The presence of phosphate greatly inhibits the decolorization reaction by competitive adsorption on the mineral surface with the dye anion, while the addition of calcium promotes the decolorization rate of DLR dye. The decolorization rate of the dye compound rises with the increase of particle concentration and the decrease of size since the available surface sites grow in number.

Acknowledgements-This research was supported by the Natural Sciences Foundation of China (No: 29637010).

\section{REFERENCES}

Carraway E. R., Hoffmann A. J. and Hoffmann M. R. (1994) Photocatalytic oxidation of organic acids on quantum-sized semiconductor colloids. Environ. Sci. Technol. 28, 786-793.

Choi W., Termin A. and Hoffmann M. R. (1994) The role 
of metal ion dopants in quantum-sized $\mathrm{TiO}_{2}$ : correlation between photoreactivity and charge carrier recombination dynamics. J. Phys. Chem. 98, 13,669-13,679.

Davis A. P. and Huang C. P. (1990) The removal of substituted phenols by a photocatalytic oxidation process with cadmium sulfide. Wat. Res. 24, 543-550.

deKeizer A., Fokkink L. G. J. and Lyklema J. (1990) Thermodynamics of proton charge formation on oxides: microcalorimetry. Colloids Surf. 49, 149-163.

Hering J. G. and Stumm W. (1990) Mineral-Water Interface Geochemistry, eds M. F. Hochella and A. F. White, pp. 427-466. Mineralogical Society of America, Washington, DC.

Kormann C., Bahnemann D. W. and Hoffmann M. R. (1989) Environmental photochemistry: is iron oxide (Hematite) an active photocatalyst? A comparative study: $\alpha-\mathrm{Fe}_{2} \mathrm{O}_{3}, \mathrm{ZnO}, \mathrm{TiO}_{2}$. J. Photochem. Photobiol. A: Chem. 48, 161-169.

Kuo W. G. (1992) Decolorizing dye wastewater with Fenton's reagent. Wat. Res. 26(7), 881-886.

Lin S. H. and Peng ChF (1994) Treatment of textile wastewater by electrochemical method. Wat. Res. 28(2), 277282.

Meyer V., Carlsson F. H. H. and Oellermann R. A. (1992) Decolourization of textile effluent using a low cost natural adsorbent material. Wat. Sci. Tech. 26(5/6), 12051211.

Oscarson D. W., Huang P. M. and Liaw W. K. (1980) The oxidation of arsenite by aquatic sediments. $J$. Environ. Qual. 9, 700-703.

Reynaldo D. B., Kimberly A. G. and Krista A. (1995) Photocatalytic degradation of methyl-tert-butyl ether in $\mathrm{TiO}_{2}$ slurries a proposed reaction scheme. Wat. Res. 29(5), 1243-1248.

Specchia V. and Gianetto A. (1984) Powdered activated carbon in an activated sludge treatment plant. Wat. Res. 18(2), 133-137.

Stone A. T. (1986) Adsorption of organic reductants and subsequent electron transfer on metal oxide surfaces. In
Geochemical Processes at Mineral Surfaces, eds J. A. Davis and K. F. Hayes, pp. 446-461. American Chemical Society, Washington, DC.

Stone A. T. and Morgan J. J. (1984a) Reduction and dissolution of manganese(III) and manganese(IV) oxides by organics-1. Reaction with hydroquinone. Environ. Sci. Technol. 18, 450-456.

Stone A. T. and Morgan J. J. (1984b) Reduction and dissolution of manganese(III) and manganese(IV) oxides by organics - 2. Survey of the reactivity of organics. Environ. Sci. Technol. 18, 617-624.

Stone A. T. (1987) Reduction and dissolution of manganese(III/IV) oxides by substituted phenols. Environ. Sci. Technol. 21(10), 979-988.

Strehlow W. H. and Cook E. L. (1973) Compilation of energy band gap in elemental and binary compound semiconductors and insulators. J. Phys. Chem. Ref. Data 2(1), 163-199.

Sun T. H., Lin ShN, Yu ZhM and Chen L. (1991) A study on the treatment of difficult-to-degrade dyeing wastewater of high concentration by bioferric process. China Environmental Science 11(2), 138-142.

Sunda W. G. and Kieber D. J. (1994) Oxidation of humic substances by manganese oxide yields low-molecularweight organic substrates. Nature 367, 62-64.

Ulrlch H. J. and Stone A. T. (1989) Oxidation of chlorophenols adsorbed to manganese oxide surfaces. Environ. Sci. Technol. 23, 421-428.

Waite T. D., Wrgley I. C. and Szymczak R. (1988) Photoassisted dissolution of a colloidal manganese oxide in the presence of fulvic acid. Environ. Sci. Technol. 22(7), $778-785$.

Wehrli B. (1990) Redox reaction of metal ion at mineral surfaces. In Aquatic Chemical Kinetics, ed. W. Stumm, pp. 311-336. John Wiley and Sons, New York.

Yu X. and Jiang C. H. (1984) Modern Marine Deposited Mineral and its Studies on X-ray Diffraction Spectrum. Science Press, Beijing. 